\title{
Endocrine causes of systemic hypertension in children and adolescents: a clinical review
}

This article was published in the following Dove Press journal:

Pediatric Health, Medicine and Therapeutics

26 April 201 I

Number of times this article has been viewed

\section{Manmohan Kamboj' \\ Vibha Gupta ${ }^{2}$ \\ Alfonso Torres ${ }^{2}$ \\ Dilip R Patel ${ }^{2}$}

'Nationwide Children's Hospital, Columbus, OH, USA; ${ }^{2}$ Michigan State University, Kalamazoo Center for

Medical Studies, Kalamazoo, MI, USA
Correspondence: Manmohan Kamboj Nationwide Children's Hospital, 700 Children's drive (ED 425), Columbus, $\mathrm{OH} 43205$, USA

$\mathrm{Tel}+$ I $6 \mid 47224436$

Email manmohan.kamboj@ nationwidechildrens.org
Abstract: Hypertension has been well recognized as a major contributor of chronic cardiovascular disease, resulting in significant morbidity and mortality not only in adults but also in children and adolescents. Primary or essential hypertension refers to cases where no underlying etiology is apparent for the high blood pressure, and accounts for a majority of the patients. Secondary hypertension refers to a much smaller group of patients in whom the blood pressure elevation may be attributed to an underlying cause. With improved diagnostic techniques, some cases of previously diagnosed essential hypertension may be found to have an underlying etiology. Endocrine causes account for a relatively small proportion of all patients with hypertension. In the following discussion, only secondary hypertension due to endocrinerelated causes will be discussed.

Keywords: primary hyperalsosteronism, paraganglioma, beta-hydroxy-steroid dehydogenase deficiency, Liddle syndrome, Gordon syndrome

\section{Introduction}

An accurate assessment of blood pressure (BP) is very important. Use of appropriate BP cuffs, reliable BP measuring apparatus, and availability of trained staff for obtaining consistent measurements is key. It is also important to correlate a high blood pressure by comparing with appropriate reference standards. The National Heart, Lung, and Blood Institute Task Force in Blood Pressure Control in Childhood has provided reference standards for blood pressure according to age, sex, and height percentiles and offer 50th, 90th, 95th, and 99th percentiles for blood pressure for each of these categories. $^{1,2}$

Limitations still remain about possible ethnic differences, normal diurnal variations in blood pressures, and also the fact that only in-office BP measurements are generally used, and changes in BP over the day in daily routine situations is not measured. Several BP measurements on different days need to be monitored before making final decisions. Ambulatory BP monitoring devices worn over several days may offer more insight into BP variations over the day.

A group of disorders generally referred to as monogenic or low renin causes of hypertension include primarily underlying disorders of the adrenal steroid pathway as well as renal mechanisms involved with $\mathrm{Na}^{+} / \mathrm{K}^{+}$channels. ${ }^{3,4} \mathrm{~A}$ second group of disorders include a primary endocrine dysfunction related to thyroid, parathyroid, adrenal, and cortisol metabolism. Other syndromic conditions such as Turner syndrome, metabolic syndrome, and diabetes mellitus are inherent risk factors for hypertension. Besides these 
basic underlying disorders, iatrogenic hypertension needs to be considered, especially in patients taking glucocorticoids, thyroid hormone replacement therapy with estrogens or androgens. These different groups of disorders are explained in more detail below.

\section{Primary hyperaldosteronism (PA)}

Primary hyperaldosteronism is characterized by excessive aldosterone secretion and may be due to aldosterone producing adenoma (APA) and idiopathic hyperaldosteronism adrenal hyperplasia (IHA), representing $80 \%$ and $20 \%$ of cases respectively. ${ }^{5-8}$ Previously believed to be uncommon, more recently there is increased recognition of specific cardiovascular morbidity and mortality related to excessive aldosterone secretion. These effects are related to the pro-inflammatory and pro-fibrotic properties of aldosterone on the heart, blood vessels, and the kidney and seem to be independent of the severity of the hypertension. Compared with patients with similar levels of hypertension, patients with hyperaldosteronism have more diastolic dysfunction, atrial fibrillation, left ventricular hypertrophy, and an increased incidence of cardiovascular complications including myocardial infarction. Patients with resistant hypertension have increased aldosterone associated with brain natriuretic peptide (BNP) and atrial natriuretic peptide levels and proteinuria, in association with high sodium diet, indicating intravascular volume expansion. These patients demonstrate resistance to usual doses of thiazides, but respond with diuresis to specific mineralocorticoid receptor antagonists. ${ }^{9}$

In the last 15 years, using the plasma aldosterone concentration (PAC) to plasma renin activity (PRA) ratio as a casefinding test for PA, followed by confirmatory testing, PA has surged as the most common cause of secondary hypertension. Tables 1 and 2 detail the laboratory findings in reference to

Table I Plasma aldosterone plasma renin activity, plasma ARR values, and cause of hyperaldosteronism

\begin{tabular}{lll}
\hline Condition & $\begin{array}{l}\text { Plasma aldosterone } \\
\text { (ng/d) to plasma renin } \\
\text { activity }(\mathbf{n g} / \mathbf{m L} / \mathbf{h}) \text { [ARR] }\end{array}$ & Aldosterone \\
\hline $\begin{array}{l}\text { Normotensive } \\
\text { Essential } \\
\text { hypertension }\end{array}$ & $>24$ & \\
$\begin{array}{l}\text { Primary } \\
\text { hyperaldosteronism }\end{array}$ & $>27$ & 12 \\
$\begin{array}{l}\text { Idiopathic } \\
\text { hyperaldosteronism }\end{array}$ & $>27$ & \\
$\begin{array}{l}\text { Adrenal hyperplasia } \\
\text { Aldosterone }\end{array}$ & 100 & $\geq 20$ \\
producing adenoma & & \\
\hline
\end{tabular}

Abbreviation: ARR, aldosterone renin ratio.
Table 2 Factors that interfere with the plasma aldosterone renin ratios (ARRs)

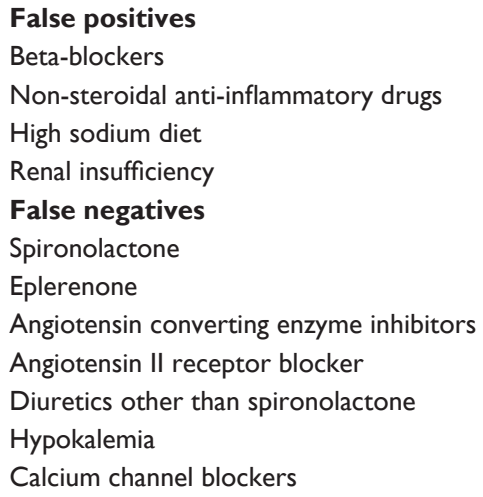

False positives

Beta-blockers

Non-steroidal anti-inflammatory drugs

High sodium diet

Renal insufficiency

False negatives

Spironolactone

Eplerenone

Angiotensin converting enzyme inhibitors

Angiotensin II receptor blocker

Diuretics other than spironolactone

Hypokalemia

Calcium channel blockers

PRA and plasma aldosterone ratios and the factors that may influence the accuracy of these measurements. ${ }^{5,10}$

\section{Familial hyperaldosteronism (FHA)}

There are three different types of FHA known to date, namely FHA I, FHA II, and FHA III. ${ }^{11-18}$ Early onset of hypertension and consequent early target organ damage are features of these inheritable groups of disorders. The definitive gene defect in FHA type 1 is known, while active research continues to detect the definitive genetic mutations in types II and III. ${ }^{11}$ A careful family history is essential for early diagnosis and institution of early treatment to minimize morbidity. ${ }^{11}$

\section{FHA I}

FHA I, also known as glucocorticoid remediable aldosteronism (GRA), is an autosomal dominant familial form of hypertension caused by chimeric gene duplications occurring between the adjacent genes for aldosterone synthase and $11 \beta$-hydroxylase genes located in chromosome $8 .^{12,13}$ This chimeric gene has a new structure, fusing the regulatory sequence of $11 \beta$-hydoxylase onto coding sequences that specify aldosterone synthase. ${ }^{12,13}$

The clinical presentation is considerably variable. The hypertension may be mild with normal laboratory findings and be considered as essential hypertension; or it may be severe leading to development of stroke, particularly in men between 20 and 40 years of age. There may be severe hypertension presenting in early childhood which can be very difficult to treat if the specific diagnosis is not established. The diagnosis is facilitated if there is a family history of severe hypertension following an autosomal dominant pattern of inheritance, if the hypertension develops early, and if hypokalemia develops after the use of diuretic therapy. A useful screening test for the identification of these patients is the finding of an elevated aldosterone renin ratio 
(ARR), usually $>30$. Since the test is not specific for this disorder, further evaluation becomes necessary. ${ }^{13}$ Urinary 18-oxocortisol and 18-hydroxycortisol levels are elevated in patients with GRA. ${ }^{13}$ Dexamethasone suppression testing may be undertaken in which the aldosterone plasma levels are measured before and after the administration of $0.5 \mathrm{mg}$ of dexamethasone orally every 6 hours for 4 days. In GRA, this results in suppression of plasma aldosterone to very low levels. The test, however, is not specific for GRA, as other conditions associated with hyperaldosteronism may also show similar results. However genetic testing now offers specific diagnosis.

The treatment for GRA is aimed at suppression of aldosterone by administration of glucocorticoids. ${ }^{13}$ The dose of glucocorticoids used should be the minimum necessary to suppress aldosterone without causing Cushing syndrome and linear growth retardation. Other medications that are helpful include the use of a specific mineralocorticoid receptor blocker such as spironolactone or eplerenone. Low sodium diet should be followed as well.

\section{FHA II}

FHA II is an autosomal dominant condition characterized by increase production of aldosterone due to adrenocortical hyperplasia or APA. ${ }^{11}$ This differs from FHA I in that the aldosterone secretion is not suppressible by glucocorticoids. Genetic analysis demonstrates that it is not related to the hybrid CYP11B1/CYP11B2 mutation located in the long arm of chromosome 8 responsible for the FHA I. ${ }^{11,14,15}$ Several families with FHA II have been described in Australia, South America, and in Italy, and although the specific gene mutation has not been identified, linkage analysis studies in these families indicate that the locus of the abnormal gene seems to be within the 7 p22 region. ${ }^{14,15}$ Patients with FHA II usually do not present in infancy. Surgical correction is indicated in the presence of unilateral APA; medical treatment is indicated in the presence of bilateral adrenal hyperplasia, including evaluating the response to the specific blockade of the MR-A by spironolactone. ${ }^{11,14,15}$

\section{FHA III}

A Mendelian form of FHA is reported that differs clinically and biochemically from previously described cases. ${ }^{16,17}$ The index case was a 5 year old boy that presented with headache, polyuria polydipsia, and hypertension (blood pressure of 230/140 mm Hg), hypokalemia, hyperaldosteronism with urinary aldosterone excretion of $150 \mu \mathrm{g} / \mathrm{d}$. No adenoma was detected. Despite vigorous medical treatment, the blood pressure did not respond to treatment. Bilateral adrenalectomy at
9 years resulted in normalization of the blood pressure and correction of the hypokalemia. The adrenals were found to be grossly enlarged with histology consistent with nodular hyperplasia of the zona fasciculata. Twenty-six years later, two daughters of the index case, ages of 4 and 7 years were evaluated for hypertension. The BPs were noted to be 188/140 mm Hg and 148/114 mm Hg. They also presented with severe hypokalemia, hyperaldosteronism (aldosterone levels $>100 \mathrm{ng} / \mathrm{dL}$ ) and decreased PRA of 0.3 and $0.2 \mathrm{ng} / \mathrm{mL} / \mathrm{h}$. The urine revealed markedly elevated hybrid steroids 18-oxocortisol and 18-hydroxycortisol. But these children did not respond to treatment with dexamethasone at a dose of $0.5 \mathrm{mg}$ twice daily. They failed to normalize their blood pressures, and surprisingly were noted to show a doubling of the plasma aldosterone levels. The failure of the hypertension to respond to aggressive medical treatment made bilateral adrenalectomy the ultimate therapeutic option. The adrenal glands were grossly enlarged with histology revealing histological atrophy of the zona glomerulosa and diffuse hyperplasia of the zona fasciculata. This has since then been labeled as FHA III differing from FHA types I and II in several aspects. The specific genetic mutation for FHA III has not been described as yet. ${ }^{18}$

\section{Hereditary paragangliomal pheochromocytoma (PGL/PCC) syndromes}

PGLs and PCCs are tumors that develop from neural crest cell lineage, stain positively for chromaffin, and produce catecholamines. ${ }^{19}$ Tumors that originate from the adrenal medulla are designated as PCCs; tumors that are located in extra adrenal position are called PGLs. ${ }^{19}$ PGLs are located along the paravertebral region extending from the neck to the pelvis; a few cases have been described in the bladder. These tumors may also be found in association with MEN2 and von Hippel-Lindau syndrome. ${ }^{19}$ The sympathetic PGLs secrete catecholamines. ${ }^{19,20}$ Of the parasympathetic PGLs, most are nonsecretory. The PGLs and PCCs are very rare in children. The age of presentation is more often during the teen years; the male to female ratio is $1: 1$. The clinical manifestations may vary greatly. Symptoms due to tumor effect may be seen in $30 \%$ of patients presenting with abdominal pain and abdominal distention, or noted as an incidental mass during imaging study for another reason. The clinical features present are due to hypersecretion of catecholamines and may result in paroxysmal or sustained hypertension, headache, and palpitations. Secondary symptoms include profuse sweating, flushing, nausea, vomiting, diarrhea, anxiety, and tremors. Although episodic symptomatology is 
described, the hypertension in the pediatric population tends to be constant. This diagnosis should be ruled out in children and adolescents with significant hypertension. ${ }^{19}$

The catecholamines secreted by PGLs/PCCs may be epinephrine, norepinephrine, or dopamine. ${ }^{20}$ The recommended case detection test is the plasma fractionated metanephrines achieving $82 \%-97 \%$ specificity with $96 \%-99 \%$ of sensitivity. ${ }^{20}$ Negative test results exclude the existence of catecholamines. Steps to avoid false positive that are recommended include obtaining resting plasma fractionated metanephrines from a supine venipuncture, after voiding or discontinuing interfering medications; and increasing the diagnostic cutoff values; using additional testing measures such as a 24-hour urine fractionated metanephrine or clonidine suppression test. Confirmatory testing with plasma chromogranin A or urine fractionated metanephrines is recommended. ${ }^{20}$ After confirmatory diagnosis in a proband, molecular genetic testing for succinate dehydrogenase subunit B (SDHB), succinate dehydrogenase subunit $\mathrm{C}$ (SDHC), and succinate dehydrogenase subunit D (SDHD) is indicated in all individuals known to have or suspected to have PGL/PCC syndrome. A high index of suspicion should exist for children presenting at early age with bilateral adrenal tumor or with extra-adrenal or multiple tumors. The absence of a family history or other clinical features suggesting hereditary syndromes does not preclude the need for genetic testing. Imaging studies are further used for tumor localization. The diagnostic sensitivity and specificity of computed tomography $(\mathrm{CT})$ and magnetic resonance imaging (MRI) are equivalent. ${ }^{123}$ I-metaiodobenzylguanidine (MIBG) scintigraphy has greater specificity for localization but less sensitivity. It may be useful to further characterize masses detected by CT or MRI.

The treatment of PCCs and PGLs is surgical with preoperative preparation of the patient with $\alpha$-adrenergic receptor blockers and $\beta$-adrenergic receptor blockers. ${ }^{21}$ The incidence of malignancy is more than $40 \%$, particularly in pediatric patients. Chemotherapy may also be necessary. The long-term prognosis for benign PGLs/PCCs is excellent, with $100 \%$ survival at 15 years of follow up; in contrast, the 15 years survival rate for malignant PGLs/PCCs is $31 \%{ }^{21}$

\section{Syndrome of apparent mineralocorticoid excess ( I I- $\beta$ - hydroxysteroid dehydrogenase deficiency type 2}

In mineralocorticoid sensitive target tissues such as the principal cell in the cortical collecting duct, the mineralocorticoid receptor (MR) is not selective and is unable to distinguish between the glucocorticoid cortisol and its natural ligand aldosterone. ${ }^{22}$ The enzyme 11- $\beta$-hydroxysteroid dehydrogenase type-2 (11- $\beta$-HSD2) converts the hormonally active cortisol into inactive cortisone conferring specificity to the MR. ${ }^{23}$ Inactivating mutations in the gene encoding for the enzyme $11-\beta$-HSD 2 result in the autosomal recessive condition now referred to as syndrome of apparent mineralocorticoid excess (sAME) ${ }^{22,23}$ Normally, the plasma cortisol concentrations are 100-1000 times higher than aldosterone levels. In this situation, this enzyme defect causes excessive amounts of cortisol to remain and not be converted to cortisone. The cortisol in these circumstances acts as a powerful mineralocorticoid and causes cortisol-mediated hypertension. There are similarities with the clinical manifestations of dark licorice gluttony that induces inhibition of 11- $\beta$-hydrosteroid dehydrogenase type-2, giving rise to a similar picture. ${ }^{22,23}$

The clinical manifestations are related to the severity of the mutation. Severe mutations manifest early, with intrauterine growth retardation, failure to thrive, polyuria, polydipsia, low renin hypertension, low aldosterone levels, hypokalemia metabolic alkalosis hypercalciuria, and nephrocalcinosis. ${ }^{22,23}$ Less severe mutations manifest in adolescence or later in life, with hypertension. Complications include left ventricular hypertrophy, cerebrovascular accidents, and death, which may occur in infancy, adolescence, or later in life. Biochemical abnormalities include low renin, low aldosterone, and low or normal potassium. The levels of deoxycorticosterone (DOC) and corticosterone are normal. The most important biochemical parameter findings are in the urine, with elevation of cortisol (THF $+5 \alpha \mathrm{THF}$ ) to cortisone (THE) metabolites, ie, $(\mathrm{THF}+5 \alpha \mathrm{THF}) / \mathrm{THE}$ ratio, many times noted to be 10 times the normal values..$^{22-24}$

The treatment modalities include a low sodium diet, correction of hypokalemia, and a spironolactone or other MR antagonist. Blocking ENaC with amiloride seems logical; however, the administration of glucocorticoids will aggravate the condition. Calcium channel blockers may also have a role in treatment.

\section{Familial hyperkalemic hypertension (FHHt) pseudohypoaldosteronism type 2 (PHA2, Gordon syndrome)}

PHA2 is an autosomal dominant disorder characterized by the triad of hypertension, hyperkalemia, and normal glomerular filtration rate. ${ }^{24}$ Other features of the syndrome include low plasma renin activity and low aldosterone, muscle weakness, hypercalciuria, and distal renal tubular acidosis. ${ }^{24}$ Some of these children may present with short stature. Severe 
hypertension generally develops in the second to third decade. Clinical experience has shown that hypertension and hyperkalemia respond to the administration of thiazide diuretics. It has also been observed that the administration of sodium with poorly reabsorbable anions such as bicarbonate or sulfate decrease hypertension and hyperkalemia, indicating that FHHt is a distal nephron disorder of excessive chloride reabsorption (chloride shunt). ${ }^{24}$

Mutation in two related genes WINK4 and WINK1, coding for a family of serine-threonine (with no lysine) kinases have been found to be responsible for the development of PHA2. ${ }^{25-27}$ Both kinases are highly expressed in the kidney and also in the epithelia involved in chloride transport in other tissues. WINK4 is expressed predominantly along the aldosterone sensitive distal nephron (ASDN). WINK1 exists in two forms, one is diffusely expressed in many tissues and is known as the full-length kinase-sufficient WINKI (L-WINKI) and a second shorter isoform that is kidney specific and is abundantly distributed in the ASDN. ${ }^{25-27}$ Recently published whole genome association study has identified Ste20 related proline-alanine rich kinase (SPAK, also known as STK39) as a hypertension susceptibility gene in the general population. ${ }^{25}$ WINK 4 inhibits sodium reabsorption by reducing the expression of NCC in the plasmalemma. Missense mutations in WINK 4 block this inhibitory activity, and as a result there is an increase in the apical expression of the transporter as well as sodium reabsorption. The effect of the missense mutation of WINK4 on ROMK is less clear but seems to work in an opposite manner, causing a decrease in potassium excretion. ${ }^{26}$

In PHA2 there is there is loss of inhibition of NCC and increase of the inhibition of ROMK, in addition to an increase in paracellular permeability to chloride in the medullary collecting kidney cells. It is also known that WINK4-mediated negative regulation of NCC activity is in turn inhibited by WINK1. 27,28 Treatment of Gordon syndrome is with a low sodium diet and administration of thiazide diuretics, which are the diuretics of first choice for this condition. Loop diuretics are able to normalize the blood pressure and hyperkalemia, but worsen the hypercalciuria.

\section{Liddle syndrome}

Liddle syndrome was initially described by Liddle in 1963 in a 16-year-old adolescent female in a family in which multiple siblings developed early onset of severe hypertension and frequent occurrence of strokes following an autosomal dominant pattern of inheritance. ${ }^{22,29,30}$ Laboratory evaluation revealed hypokalemia, metabolic alkalosis, suppressed plasma renin activity, and low aldosterone levels. ${ }^{22,29,30}$ At that time this condition was called pseudohyperaldosteronism. These patients are cured by renal transplantation, therefore demonstrating that the abnormality resides in the kidney and is not the result of a circulating factor. Today we know that Liddle syndrome results from a gain of function mutation in the genes encoding for the $\beta$ and $\gamma$ subunits of $\mathrm{ENaC}$ on chromosome 16p13-p12. Alterations in the genes render the proteins resistant to the normal degradation by the family of ubiquitin ligases (Nedd4 pathway). ${ }^{29,30}$ As a result, the number of channels is increased, and they remain active therefore causing an increase in sodium and water reabsorption and increased potassium and $\mathrm{H}^{+}$excretion. ${ }^{29,30}$ Liddle syndrome is refractory to most antihypertensive medications; however, the understanding of the basic mechanism of the disease has facilitated a rational treatment. Amiloride or triamterene block $\mathrm{ENaC}$, therefore preventing $\mathrm{Na}^{+}$reabsorption, and together with a low sodium diet, allows for control of the hypertension, as well as the resolution of the hypokalemia and metabolic alkalosis. ${ }^{29,30}$ Mineralocorticoid blockade with spironolactone or eplerenone does not offer therapeutic effect. Renal transplantation is curative.

\section{Activating mineralocorticoid receptor mutation exacerbated by pregnancy}

A newly discovered missense mutation of the MR results in a substitution of lysine for serine in codon $810(\mathrm{~S} 810 \mathrm{~L})$. $^{31,32}$ Further evaluation reveals that the carriers of $\mathrm{MR}_{\mathrm{L} 810}$ develop hypertension before the age of 20 years, and the women in the family who carried the mutation experience a severe exacerbation of the hypertension during pregnancy. ${ }^{31,32}$ The (S810L) is a gain of function mutation in the human MR gene located on 4q31.1. With this mutation, the specificity of the receptor is altered in such a way that hormones lacking the 21-hydroxyl group such as cortisone and progesterone becomes agonistic and activate $\mathrm{MR}_{\mathrm{L} 810}$. During pregnancy, progesterone levels increase 100-fold and may be responsible for the dramatic increase in blood pressure in these women. During pregnancy there is an avid sodium and water retention resulting in volume expansion and hypertension with low aldosterone levels. It is important to remember that the disorder does not respond to glucocorticoids or spironolactone, and the use of spironolactone aggravates the hypertension. Delivery of the fetus, however, improves the condition.

It is reasonable to infer that the onset of early hypertension in both male and female carriers of $\mathrm{MR}_{\mathrm{L} 810}$ may be due 
to a permanent increase in sodium reabsorption in the distal nephron due to activation of $\mathrm{MR}_{\mathrm{L} 810}$ by cortisone. ${ }^{32}$

\section{Hypertension due to a basic underlying endocrine disorder Thyroid disorders}

Hypertension is reported both in hyper- and hypothyroidism. Patients with hyperthyroidism commonly have systolic hypertension. ${ }^{33}$ Additionally, increased cardiac output and increased cardiac contractility in the setting of decreased peripheral vascular resistance resulting in the common finding of widened pulse pressure in these patients. ${ }^{33,34}$ Activation of the renin-angiotensin system (RAS) seems to be contributory to the hypertension in hyperthyroidism, and angiotensin II antagonists are noted to lower the blood pressure. Hypothyroidism has also been reported to be associated with hypertension as well; however, this continues to be controversial. $^{33,34}$ Treatment of the underlying thyroid dysfunction results in normalization of high blood pressure.

\section{Cushing's syndrome}

Cushing's syndrome results from excessive exposure to glucocorticoids, which may be endogenously produced or exogenously administered. Endogenous glucocorticoid may be produced as a result of increased CRH (corticotropin releasing hormone), ACTH (adrenocorticotropic hormone), or cortisol production; and ectopic tumors secreting $\mathrm{CRH}$ or ACTH and adrenal tumors. Patients with Cushing's syndrome exhibit predominantly diastolic hypertension, which may be due to increased angiotensinogen, increased peripheral vascular response to adrenergic agonists, and also possibly due to activation of the MRs by large amounts of cortisol. ${ }^{35-41}$

\section{Parathyroid disorders and hypercalcemia}

Hyperparathyroidism is frequently associated with hypertension, and this may be seen even when the primary hyperparathyroidism is mild. The exact etiology or mechanism of hypertension in hyperparathyroidism is not clear. Additionally, there is no definite improvement of hypertension in patients even when their primary hyperparathyroidism has been treated. ${ }^{41-43}$ Intracellular hypercalcemia and abnormal calcium regulation are believed to be causative for hypertension.

\section{Congenital adrenal hyperplasia $(\mathrm{CAH})$}

$\mathrm{CAH}$ results from defects in the steroidogenic enzymes involved in the adrenal steroid biosynthetic pathway.
The level and severity of the enzymatic defect determines clinical features and the specific biochemical profile. 21 hydroxylase gene mutations are responsible for the most common form of CAH. However, it is generally not associated with hypertension. $\mathrm{CAH}$ associated with hypertension mainly includes enzymatic mutations in $11 \beta$-hydroxylase (CY 11ß1) and $17 \alpha$-hydroxylase/17, 20 lyse (CYP 17).

$\mathrm{CAH}$ due to $11 \beta$-hydroxylase deficiency accounts for about $5 \%$ of all patients with CAH. CY $11 \beta 1$ is involved in the conversion of 1-deoxycorticosterone (DOC) to corticosterone and 11-deoxycortisol to cortisol. Therefore, secretion of corticosterone and cortisol is impaired. However, secondary to increased ACTH, the levels of DOC and 11-deoxycortisol are increased. Markedly increased levels of DOC result in hypertension. DOC being a mineralcorticoid also causes suppression of renin and angiotensin, and subsequently low levels of aldosterone as well. Therefore, this is one of the inherited forms of low renin hypertension. Hypertension in these cases is usually mild but may occasionally be severe. Like other CAH entities, CYP11 $\beta 1$ deficiency is also inherited in an autosomal recessive manner. Diagnosis is primarily biochemical by demonstration of elevated levels of DOC and 11-deoxycortisol in blood and tetrahydro-11-deoxycortisol in urine. Genetic diagnosis may also be obtained.

Treatment of these patients is achieved by glucocorticoid replacement, which by negative feedback inhibits the excessive ACTH secretion, thereby lowering levels of DOC. This usually is therapeutic for treatment of hypertension as well. However, in severe cases, temporary treatment with antihypertensives may be undertaken until the more specific treatment starts to work in these patients.

CYP17 deficiency causes one of the uncommon forms of CAH. CYP17 is responsible for conversion of pregnenolone to $17 \mathrm{OH}$ pregnenolone, and progesterone to $17 \mathrm{OH}$ progesterone. Therefore, there is cortisol deficiency but production of large amounts of corticosterone, which can also bind to the glucocorticoid receptor, and DOC, which results in low renin hypertension. The treatment approach is similar to that discussed under $11 \beta$ hydroxylase deficiency.

\section{Metabolic syndrome, obesity, diabetes mellitus}

Hypertension is commonly associated with obesity and metabolic syndrome. Metabolic syndrome has been shown to be associated with a higher risk of cardiovascular disease. ${ }^{44,45}$ 
This increased risk is seen to be related to insulin resistance rather than obesity itself. ${ }^{44-48}$ Many patients with type 2 diabetes mellitus (T2DM) may have hypertension at diagnosis, while most patients with type 1 diabetes mellitus develop hypertension subsequent to nephropathy. ${ }^{49}$ Long term, large trials for T2DM such as the UKPDS (United Kingdom Prospective Diabetes Study) have emphasized the importance of aggressive antihypertensive therapy for all patients with $\mathrm{T} 2 \mathrm{DM}$, so as to minimize the risks of cardiovascular heart disease. ${ }^{1,49,50}$

\section{Turner syndrome (TS)}

TS is a chromosomal disorder in females with an incidence of 1:2000 to 1:5000, characterized by the partial or complete absence of one of the X chromosomes. The two almost constant features of TS are short stature and ovarian dysgenesis. Aside from these features, there is a high association of multiple other congenital anomalies involving the renal, endocrine, and cardiovascular systems. Cardiovascular disease risk generally includes aortic valvular disease and hypertension; coarctation of aorta and aortic dissection may be seen later in adulthood. The risk of hypertension was documented in a study which documented $30 \%$ of TS girls or young women were mildly hypertensive, and $50 \%$ had abnormal blood pressure profile on ambulatory BP monitoring. ${ }^{51}$ TS girls should have their blood pressure monitored and followed closely. Hypertension in TS girls should be aggressively and appropriately treated to minimize the risks of aortic dissection.

\section{latrogenic hypertension}

A comprehensive history in patients with hypertension should include details of medications. Many medications used in endocrinology can lead to high blood pressure. Most important of these probably includes steroids. These may be glucocorticoids used for replacement therapy in $\mathrm{CAH}$, adrenal insufficiency, or in nonendocrine conditions such as autoimmune conditions, pulmonary conditions, in chemotherapy protocols, mineralocorticoids for replacement in salt wasting $\mathrm{CAH}$ conditions, and oral contraceptive pills with estrogen-progestin combinations. It is important to remember that physiologic glucocorticoid doses used for replacement therapy as in CAH or adrenal insufficiency generally will not cause hypertension. Hypertension due to glucorticoids will be seen in scenarios of utilization of pharmacologic doses. A supratherapeutic dose of thyroid hormone supplementation also may increase the risk of hypertension as well. Patients on all these treatment regimens should have regular and close follow-up of their blood pressures.

\section{Conclusion}

There is no simple, specific, reliable approach for the diagnosis of the monogenic forms of hypertension. However the clinical presentation, family history, physical examination, and basic laboratory studies for electrolyte abnormalities along with a high index of suspicion may together provide helpful clues toward diagnosis. ${ }^{52}$ All these factors should be considered carefully in any child or adolescent presenting with hypertension. A common finding in all the monogenic forms of hypertension is the low levels of plasma renin activity at presentation. Once therapy is initiated, the plasma renin levels are modified, and measurements for diagnostic purposes after initiation of treatment will not be helpful. Along with a plasma renin activity (PRA), aldosterone levels should be measured as well. The PRA to aldosterone ratio currently is the most used screening test for the diagnosis of primary hyperaldosteronism and aldosterone producing adenoma.

\section{Disclosure}

The authors report no conflicts of interest in this work.

\section{References}

1. Chobanian AV, Bakris GL, Black HR, et al; for the National Heart, Lung, and Blood Institute, the Joint National Committee on Prevention, Detection, Evaluation, and Treatment of High Blood Pressure, and the National High Blood Pressure Education Program Coordinating Committee. The seventh report of the Joint National Committee on Prevention, Detection, Evaluation, and Treatment of High Blood Pressure: the JNC report. JAMA. 2003;289(19):2560-2572.

2. National High Blood Pressure Education Program Working Group on High Blood Pressure in Children and Adolescents. The Fourth Report on Diagnosis, Evaluation, and Treatment of High Blood Pressure in Children and Adolescents. Pediatrics. 2004;114(2):555-576.

3. Reeves WB, Andreoli TE. Sodium Chloride Transport in the Loop of Henle, Distal convoluted Tubule, and Collecting Duct. In: Alpern RJ, Herbert SC, editors. Seldin and Giebisch's The Kidney Physiology and Pathophysiology. 4th ed. Philadelphia: Academic Press Elsevier; 2008:849-887.

4. Verrey F, Hummler E, Schild L, Bernard C. Mineralocorticoid action in the aldosterone sensitive distal nephron. In: Alpern RJ, Herbert SC, editors. Seldin and Giebisch's The Kidney Physiology and Pathophysiology. 4th ed. Philadelphia: Academic Press Elsevier; 2008:889-924.

5. Kater CE, Biglieri EG. The syndromes of low-renin hypertension: "separating the wheat from the chaff". Arq Bras Endocrinol Metab. 2004;48(5): 674-681.

6. Parthasarathy HK, MacDonald TM. Primary hyperaldosteronism and other forms of mineralocorticoid hypertension. In: Lip GYH, Hall JE, editors. Comprehensive Hypertension. Philadelphia: Mosby Elsevier; 2007:809-825.

7. Young WE. Primary hyperaldosteronism: renaissance of a syndrome. Clin Endocrinol. 2007;66(5):607-618. 
8. Fardella CE, Mosso L, Gómez-Sanchez C, et al. Primary hyperaldosteronism in essential hypertensives: prevalence, biochemical profile, and molecular biology. J Clin Endodrinol Metab. 2000;85:1863-1867.

9. Gaddam K, Corros C, Pimenta E, et al. Rapid reversal of left ventricular hypertrophy and intracardiac volume overload in patients with resistant hypertension and hyperaldosteronism: a prospective clinical study. Hypertension. 2010;55(5):1137-1142.

10. Kempers MJ, Lenders JW, Van Outheusden L, et al. Systematic review: diagnostic procedures to differentiate unilateral from bilateral adrenal abnormality in primary aldosteronism. Ann Intern Med. 2009;151(5):357-358.

11. Quack I, Vonend O, Rump LC. Familial hyperaldosteronism I-III. Horm Metab Res. 2010;42(6):424-428.

12. Lifton RP, Dluhy RG, Powers M, et al. Hereditary hypertension caused by chimaeric gene duplications and ectopic expression of aldosterone synthase. Nat Genet. 1992;2(1):66-74.

13. Lifton RP, Dluhy RG, Powers M, et al. A chimaeric 11 beta-hydroxylase/ aldosterone synthase gene causes glucocorticoid- remediable aldosteronism and human hypertension. Nature. 1992;355(6357):262-265.

14. Sukor N, Mulatero P, Gordon RD, et al. Further evidence for linkage of familial hyperaldosteronism type II at chromosome $7 \mathrm{p} 22$ in Italian as well as Australian and South American families. J Hypertens. 2008;26(8):1557-1582.

15. Torpy DJ, Gordon RD, Lin JP, et al. Familial hyperaldosteronism type II: description of a large kindred and exclusion of the aldosterone synthase (CYP11B2) gene. J Clin Endocrinol Metab. 1998;83(9):3214-3218.

16. Geller DS, Zhang J, Wisgerhof MV, Shakleton C, Kashgarian M, Lifton RP. A novel from of human mendelian hypertension featuring nonglucocorticoid-remediable aldosteronism. J Clin Endocrinol Metab. 2008;93(8):3117-3123.

17. Friederich C, Luft MD. Mendelian forms of human hypertension and mechanisms of disease. Clin Med Res. 2003;1(4):291-300.

18. Mulatero P. A new form of hereditary primary aldosteronism: familial hyperaldosteronism type III. J Clin Endocrinol Metab. 2008;93(8): 2972-2974.

19. Vorhess ML. Adrenal medulla, sympathetic nervous system and multiple endocrine adenomatosis. In: Rudolph AM, ed. Pediatrics. Norwalk, CT: Appleton and Lange; 1987:1497.

20. Algeciras-Schimnich A, Preissner CM, Young WF Jr, Singh RJ, Grebe SK. Plasma chromogranin A or urine fractionated metanephrines follow-up testing improves the diagnostic accuracy of plasma fractionated metanephrines for pheochromocytoma. J Clin Endocrinol Metab. 2008; 93(1):91-95.

21. Pham TH, Moir C, Thompson GB, et al. Pheochromocytoma and paraganglioma in children: a review of medical and surgical management at a tertiary care center. Pediatrics. 2006;118(3):1109-1117.

22. Parthasarathy HK, Maxwell TM. Primary hyperaldosteronism and other forms of mineralocorticoid hypertension clinical approaches: secondary hypertension. In: Lip YH, Hall JE, editors. Comprehensive Hypertension. Gregory, Philadelphia: Mosby Elsevier; 2007:820.

23. Nimkarn S, New MI. Steroid 11 beta-hydroxylase deficiency congenital adrenal hyperplasia. Trends Endocrinol Metab. 2008;19(3):96-99.

24. Gordon RD. Syndrome of hypertension and hyperkalemia with normal glomerular filtration rate. Hypertension. 1986;8(2):93-102.

25. Wang Y, O'Connell JR, McArdle PF, et al. Whole-genome association study identifies STK39 as a hypertension susceptibility gene. Proc Natl Acad Sci U S A. 2009;6;106(1):226-231.

26. Kahel KT, Wilson FH, Leng Q, et al. WINK4 regulates the balance between renal $\mathrm{NaCl}$ reabsorption and $\mathrm{K}^{+}$secretion. Nat Genet. 2003;35: 372-376.

27. Hadchouel J, Delaloy C, Jeunemaitre X. WNK1 and WNK4, new players in salt and water homeostasis. Med Sci (Paris). 2005;21(1):55-60.

28. Hadchouel J, Delaloy C, Fauré S, Achard JM, Jeunemaitre X. Familial hyperkalemic hypertension. J Am Soc Nephrol. 2006;17(1): 208-217.
29. Shimkets RA, Warnock DG, Bositis CM, et al. Liddle's syndrome: heritable human hypertension caused by mutations in the beta subunit of the epithelial sodium channel. Cell. 1994;79(3):407-414.

30. Hansson JH, Nelson-William C, Suzuki H, et al. Hypertension caused by a truncated epithelial sodium channel gamma subunit: genetic heterogeneity of Liddle syndrome. Nat Genet. 1995;11(1):76-82.

31. Geller DS, Farhi A, Pinkerton N, et al. Activating mineralocorticoid receptor mutation in hypertension exacerbated by pregnancy. Science. 2000;289(5476):119-123.

32. Rafestin-Oblin ME, Souque A, Bocchi B, Pinon G, Fagart J, Vandewalle A. The severe form of hypertension caused by the activating S810L mutation in the mineralocorticoid recepror is cortisone related. Endocrinology. 2003;144(2):528-533.

33. Klein I, Ojamaa K. Thyroid hormone and the cardiovascular system: from theory to practice. J Clin Endocrinol Metab. 1994;78(5): 1026-1027.

34. Iglesias P, Acosta M, Sánchez R, Fernández-Reyes MJ, Mon C, Díez JJ. Ambulatory blood pressure monitoring in patients with hyperthyroidism before and after control of thyroid function. Clin Endocrinol (Oxf). 2005;63(1):66-72.

35. Ulick S, Wang JZ, Blumenfeld JD, Pickering TG. Cortisol inactivation overload: a mechanism of mineralocorticoid hypertension in the ectopic adrenocorticotropin syndrome. J Clin Endocrinol Metab. 1992;74(5): 963-967.

36. Cushing H. The basophil adenomas of the pituitary body and their clinical manifestations (pituitary basophilism). 1932. Obes Res. 1994;2(5): 486-508.

37. Saruta T, Suzuki H, Handa M, Igarashi Y, Kondo K, Senba S. Multiple factors contribute to the pathogenesis of hypertension in Cushing's syndrome. J Clin Endocrinol Metab. 1986;62(2):275-279.

38. Plotz CM, Knowlton AI, Ragan C. The natural history of Cushing's syndrome. Am J Med. 1952;13(5):597-614.

39. Pirpiris M, Sudhir K, Yeung S, Jennings G, Whitworth JA. Pressor responsiveness in corticosteroid-induced hypertension in humans. Hypertension. 1992;19(6 Pt 1):567-574.

40. Ross EJ, Marshall-Jones P, Friedman M. Cushing's syndrome: diagnostic criteria. Q J Med. 1966;35(138):149-192.

41. Whitworth JA. Adrenocorticotrophin and steroid-induced hypertension in humans. Kidney Int Suppl. 1992;37:S34-S37.

42. Lind L, Hvarfner A, Palmér M, Grimelius L, Akerström G, Ljunghall S. Hypertension in primary hyperparathyroidism in relation to histopathology. Eur J Surg. 1991;157(8):457-459.

43. Lind L, Ljunghall S. Pre-operative evaluation of risk factors for complications in patients with primary hyperparathyroidism. Eur J Clin Invest. 1995;25(12):955-958.

44. Ford ES. Risks for all-cause mortality, cardiovascular disease, and diabetes associated with the metabolic syndrome: a summary of the evidence. Diabetes Care. 2005;28(7):1769-1778.

45. Gami AS, Witt BJ, Howard DE, et al. Metabolic syndrome and risk of incident cardiovascular events and death: a systematic review and meta-analysis of longitudinal studies. $J$ Am Coll Cardiol. 2007; 49(4):403-414.

46. Galassi A, Reynolds K, He J. Metabolic syndrome and risk of cardiovascular disease: a meta-analysis. Am J Med. 2006;119(10):812-819.

47. McLaughlin T, Abbasi F, Lamendola C, Reaven G. Heterogeneity in the prevalence of risk factors for cardiovascular disease and type 2 diabetes mellitus in obese individuals: effect of differences in insulin sensitivity. Arch Intern Med. 2007;167(7):642-648.

48. Meigs JB, Wilson PW, Fox CS, et al. Body mass index, metabolic syndrome, and risk of type 2 diabetes or cardiovascular disease. J Clin Endocrinol Metab. 2006;91(8):2906-2912.

49. Mogensen CE, Hansen KW, Pedersen MM, Christensen CK. Renal factors influencing blood pressure threshold and choice of treatment for hypertension in IDDM. Diabetes Care. 1991;14 Suppl 4: $13-26$. 
50. Adler AI, Stratton IM, Neil HA, et al. Association of systolic blood pressure with macrovascular and microvascular complications of type 2 diabetes (UKPDS 36): Prospective observational study. $B M J$. 2000;321(7258):412-419.

51. Nathwani NC, Unwin R, Brook CG, Hindmarsh PC. The influences of renal and cardiovascular abnormalities on blood pressure in Turner syndrome. Clin Endocrinol (Oxf). 2000;52(3):371-377.
52. Johnson MC, Schneider CJ, Beck AM. Management of systemic hypertension in children and adolescents: an update. Curr Treat Options Cardiovasc Med. 2007;9(5):381-390.

Pediatric Health, Medicine and Therapeutics

\section{Publish your work in this journal}

Pediatric Health, Medicine and Therapeutics international, peerreviewed, open access journal publishing original research, reports, editorials, reviews and commentaries. All aspects of health maintenance, preventative measures and disease treatment interventions are addressed within the journal. Practitioners from all disciplines are invited to submit their work as well as healthcare researchers and patient support groups. The manuscript management system is completely online and includes a very quick and fair peer-review system. Visit http://www.dovepress. $\mathrm{com} /$ testimonials.php to read real quotes from published authors.

Submit your manuscript here: http://www.dovepress.com/pediatric-health-medicine-and-therapeutics-journal 